\title{
Estudo histopatológico do pâncreas de ratos intoxicados pelo veneno bruto do escorpião Tityus serrulatus
}

\section{Histopathologic study in rats'pancreas after injection of venom from the scorpion Tityus serrulatus}

\author{
GEÓVANA NOVAES ${ }^{1}$, ARISTIDES C. QUEIROZ², AMANDA P. QUEIROZ ${ }^{3}$, RAQUEL R. SANTOS 3 , \\ DIMITRI G. FLORES ${ }^{4}$, GUSTAVO HENKES ${ }^{4}$, BRUNO J. DUMET FERNANDES ${ }^{4}$
}

\footnotetext{
${ }^{1}$ Professora de Fisiologia. Instituto de Ciências da Saúde. UFBA

${ }^{2}$ Professor de Patologia. Faculdade de Medicina. UFBA

${ }^{3}$ Mestranda. Programa de Pós-Graduação em Nutrição. Escola de Nutrição. UFBA

${ }^{4}$ Monitor. Instituto de Ciências da Saúde. UFBA
}

Prof $^{a}$ Geóvana Novaes

Laboratório de Fisiologia do Pâncreas

Departamento de Ciências da Biorregulação

Instituto de Ciências da Saúde

Universidade Federal da Bahia

Av. Reitor Miguel Calmon s/n Vale do Canela

40.110-100 - Salvador, Bahia, Brasil

e-mail:geovana@ig.com.br

\section{Resumo}

Modificações no teor de vários componentes da secreção pancreática e alterações histopatológicas desse órgão são verificadas após injeção de veneno do escorpião Tityus serrulatus em ratos. Entre essas alterações, podem ser citadas pancreatite aguda e crônica após uma única injeção de veneno. Os achados compativeis com pancreatite aguda foram encontrados a partir de 10 minutos após a intoxicação e, 20 dias após, a maioria dos animais exibiu achados histológicos tipicos de pancreatite crônica. O objetivo do presente trabalho foi determinar a cinética das alterações pancreáticas que ocorrem ao longo do tempo, após injeção endovenosa de veneno bruto de escorpião em ratos. Os animais, após jejum de 24-48 horas, receberam uma injeção venosa, pela veia peniana, de $0,2 \mathrm{ml}$ de uma solução de cloreto de sódio (grupo controle) ou de 0,2 $\mathrm{ml}$ de uma solução contendo $300 \mathrm{mg} / \mathrm{ml}$ de veneno bruto do escorpião Tityus serrulatus (60 mg/animal). Os animais foram sacrificados em grupos de 5 a 10 cada, aos 10, 20 e 40 minutos e 1, 2, 3, 4, 6, 8, 10, 12, 14 , 16,18 e 20 dias após a injeção. $O$ pâncreas foi retirado e processado para estudo histológico. Pancreatite aguda (PA) foi observada nos grupos sacrificados após 10, 20 e 40 minutos, 24 e 48 horas após a injeção. Achados compativeis com pancreatite crônica (PC) foram detectados nos animais sacrificados entre 4 a 20 dias após a injeção. No grupo de animais sacrificados 3 dias após, observaram-se, no mesmo animal e, às vezes, no mesmo corte histológico, alterações caracteristicas de PA (degranulação, vacuolização acinar, infiltração difusa de linfócitos e lesões granulomatosas) e, surpreendentemente, de PC (dilatação ductal com rolhas protéicas, hiperplasia ductal e hiperplasia dos linfonodos peripancreáticos), caracterizando a fase de transição da pancreatite aguda para pancreatite crônica. Todos os grupos apresentaram mobilização e degranulação de mastócitos, sugerindo a participação dessas células na etiopatogênese dessas lesões. Em 50\% dos animais dos grupos sacrificados aos 18 e 20 dias após o veneno foram também observados, ao lado das lesões inflamatórias, hiperplasia das ilhotas de Langerhans.

\section{Palavras-chave}

Pancreatite aguda, pancreatite crônica, secreção pancreática, veneno de escorpião 


\section{Introdução}

Venenos de diferentes espécies de escorpiões interferem na função exócrina do pâncreas. Mohamed et al. (1978) examinaram os efeitos do escorpião Buthus quinquestriatus em estudos histopatológicos de pâncreas de camundongo. Pantoja et al. (1983), utilizando o veneno do mesmo escorpião em cães, observaram pancreatite hemorrágica aguda. Bartholomew (1970) e Sankaran et al. (1977) mostraram que o veneno bruto do escorpião Tityus trinitatis provocam aumento de secreção exócrina do pâncreas, atribuindo-o a um efeito direto do veneno nos receptores muscarínicos.

A toxina do escorpião Tityus serrulatus induz a um aumento significativo e prolongado da secreção pancreática em ratos anestesiados (NOVAES et al., 1982).

Alterações histológicas do pâncreas de ratos intoxicados com veneno de escorpião foram descritas (NOVAES et al., 1990, 1995, 1998). Essas alterações caracterizam: uma pancreatite aguda que pode ser detectada 30 minutos após a injeção venosa do veneno e persistem por, pelo menos, 48 horas; e uma pancreatite crônica observada a partir de três dias da injeção da toxina, persistindo por até 20 dias. Um outro achado freqüente nesses animais é a proliferação das células beta das ilhotas de Langerhans, caracterizando nesidioblastose (NOVAES et al., 1998).

O objetivo do presente trabalho foi fazer um estudo das alterações histológicas do pâncreas que ocorrem após intoxicação pelo veneno bruto do escorpião Tityus serrulatus em ratos, procurando estabelecer o tempo de aparecimento das lesões e detectar a transição entre os achados de pancreatite aguda e crônica. Paralelamente ao estudo da pancreatite, seria verificado o tempo de aparecimento e as características histológicas da nesidioblastose.

\section{Materiais e métodos}

\section{Animais}

Noventa e quatro ratos machos, adultos (Rattus novergicus, variedade Wistar), pesando em média $250 \mathrm{~g}$, foram colocados em gaiolas individuais e deixados em jejum das 24 às 48 horas que precediam a injeção do veneno, recebendo água ad libitum.

\section{Drogas e reagentes}

Todos os animais receberam a mesma dose do veneno bruto (60 mg), contidos em 0,2 ml, em uma única injeção intravenosa. A coloração do tecido pancreático foi feita pela hematoxilina e eosina.

\section{Procedimento}

Os animais foram separados em grupos: o controle, formado por 10 ratos que receberam injeção de $0,2 \mathrm{ml}$ de solução salina, e os tratados com o veneno do escorpião Tityus serrulatus, em uma única injeção pela veia peniana. Os animais do grupo controle foram sacrificados 3 ou 4 dias após a injeção de solução salina e os dos grupos injetados com veneno foram sacrificados imediatamente após 10, 20 e 40 minutos e $1,2,3,4,6,8,10,12,14,16,18$ e 20 dias depois da injeção de $60 \mathrm{mg}$ de veneno bruto do escorpião Tityus serrulatus, como mostra o QUADRO 1.

\section{QUADRO 1}

Grupos experimentais e intervalo de tempo entre a inoculação do veneno e o sacrificio dos animais

\begin{tabular}{ccc}
\hline Grupos & $\begin{array}{c}\text { Animais } \\
\text { (n) }\end{array}$ & $\begin{array}{c}\text { Intervalo de tempo } \\
\text { entre injeção de VB } \\
\text { e sacrificio }\end{array}$ \\
\hline 1 (controle) & 10 & $3-4$ dias \\
2 & 06 & 10 minutos \\
3 & 06 & 20 minutos \\
4 & 05 & 40 minutos \\
5 & 05 & 1 dia \\
6 & 05 & 2 dias \\
7 & 06 & 3 dias \\
8 & 05 & 4 dias \\
9 & 06 & 6 dias \\
10 & 06 & 8 dias \\
11 & 05 & 10 dias \\
12 & 05 & 12 dias \\
13 & 06 & 14 dias \\
14 & 06 & 16 dias \\
15 & 06 & 18 dias \\
16 & 06 & 20 dias \\
\hline
\end{tabular}


No dia anterior ao estabelecido para o sacrificio, os animais foram novamente postos em jejum, com água ad libitum. Após pesagem e anestesia com uretana $(1,4 \mathrm{mg} / 100 \mathrm{~g})$, os animais foram fixados em uma placa de cortiça, em decúbito dorsal, submetidos a uma laparotomia ampla e, após sua identificação, o pâncreas foi retirado em conjunto com a parte pilórica do estômago e a alça duodenal que sustenta grande parte do órgão disperso, e com o baço e linfonodos peripancreáticos.

Concluido o procedimento cirúrgico, a peça inteira foi estendida em papel de filtro embebido em formol tamponado a $10 \%$ sobre uma placa de cortiça e transferida para uma placa de Petri, contendo a mesma solução, onde permaneceu por um período de 15 a 24 horas. O pâncreas foi então isolado dos órgãos adjacentes e colocado em frasco individual, mergulhado em solução de formol tamponado a 10\% e vedado com parafilme.

\section{Estudo histológico}

Após fixação por 48 a 72 horas, o tecido foi incluído em parafina em cortes de $5 \mathrm{~mm}$, montado em lâminas histológicas e corados pela hematoxilina e eosina.

As lâminas foram observadas em microscópio óptico, com resolução de 10, 40 e 100 vezes e fotografadas.

\section{Resultados}

O estudo histológico dos pâncreas dos animais do grupo controle injetados com solução salina isotônica não apresentou quaisquer alterações. Os pâncreas dos ratos submetidos à ação do veneno de escorpião apresentaram alterações variáveis, dependendo do tempo de sacrifício dos animais após a inoculação do veneno, conforme mostra o QUADRO 2. Não houve morte de animais durante o experimento.

\section{QUADRO2}

Estudo comparativo das alterações histopatológicas provocadas pelo veneno bruto do escorpiãoTityus serrulatus nas diversas fases de estudo

\begin{tabular}{|c|c|c|}
\hline Alterações agudas & Fase de transição & Alterações crônicas \\
\hline Degranulação e vacuolização acinar & Degranulação e vacuolização acinar & - \\
\hline $\begin{array}{l}\text { Infiltração linfocitária do tecido } \\
\text { adiposo peripancreático }\end{array}$ & $\begin{array}{l}\text { Infiltração linfocitária do tecido } \\
\text { adiposo peripancreático }\end{array}$ & - \\
\hline Necrose pancreática & - & - \\
\hline $\begin{array}{l}\text { Infiltração linfocitária do tecido } \\
\text { pancreático }\end{array}$ & $\begin{array}{l}\text { Infiltração linfocitária do tecido } \\
\text { pancreático }\end{array}$ & - \\
\hline Lesões granulomatosas & Lesões granulomatosas & Lesões granulomatosas \\
\hline Mastócitos no tecido adiposo & Mastócitos no tecido adiposo & Mastócitos no tecido adiposo \\
\hline $\begin{array}{l}\text { Mastócitos nos linfonodos } \\
\text { peripancreáticos }\end{array}$ & $\begin{array}{l}\text { Mastócitos nos linfonodos } \\
\text { peripancreáticos }\end{array}$ & $\begin{array}{l}\text { Mastócitos nos linfonodos } \\
\text { peripancreáticos }\end{array}$ \\
\hline Degranulação de mastócitos & Degranulação de mastócitos & Degranulação de mastócitos \\
\hline- & $\begin{array}{l}\text { Hiperplasia dos linfonodos } \\
\text { peripancreáticos }\end{array}$ & $\begin{array}{l}\text { Hiperplasia dos linfonodos } \\
\text { peripancreáticos }\end{array}$ \\
\hline- & Dilatação ductal e ductular & Dilatação ductal e ductular \\
\hline- & Rolhas protéicas & Rolhas protéicas \\
\hline - & Hiperplasia ductal e ductular & Hiperplasia ductal e ductular \\
\hline - & - & Atrofia acinar \\
\hline
\end{tabular}




\section{Alterações histológicas agudas}

Nos animais sacrificados até 48 horas após a exposição ao veneno, as alterações foram consideradas agudas. Tais alterações eram nítidas, porém variáveis, sem apresentar relação linear com o tempo para o seu aparecimento.

As principais alterações histológicas agudas, observadas tanto no tecido pancreático, quanto no peripancreático foram: degranulação e vacuolização celular, infiltração difusa de linfócitos, lesões granulomatosas, necrose peripancreática, reação celular inflamatória, mobilização e degranulação de mastócitos.

\section{Fase de transição}

As alterações características de pancreatite aguda foram observadas nos animais sacrificados até dois dias após a injeção do veneno. No terceiro dia, a histologia do pâncreas demonstrava, em um mesmo animal e, às vezes, até em um mesmo campo microscópico, alterações características tanto de pancreatite aguda quanto de pancreatite crônica. Como, nos animais sacrificados no quarto dia após o veneno, as alterações histopatológicas eram predominantemente de pancreatite crônica, foi possivel determinar o terceiro dia como sendo o tempo em que ocorre a transição entre a pancreatite aguda e a crônica induzida pelo veneno de escorpião em ratos.

\section{Alterações histológicas crônicas}

Alterações características de pancreatite crônica foram observadas nos animais sacrifica$\operatorname{dos} 4,6,8,10,12,14,16,18$ e 20 dias após a injeção do veneno. A curva ponderal não apresentou diferenças significativas. Todos os ratos apresentaram alterações teciduais caracterizadas por inflamação tanto no tecido pancreático como no peripancreático.

Foram observadas: dilatação dos ductos intra- e extralobulares, com presença de rolhas protéicas em seu interior; hiperplasia ductular e ductal; infiltração mononuclear; granulomas; hiperplasia dos linfonodos; fibrose intersticial irregularmente distribuída e infiltração linfoci- tária; lesão inflamatória na gordura peripancreática, com exuberante presença de mastócitos no tecido gorduroso. Foi observada hiperplasia de ilhotas de Langerhans em 3 animais do grupo sacrificado aos 18 dias (50\%) e em 3 do grupo sacrificado aos 20 dias (50\%).

\section{Discussão}

A evolução de uma pancreatite aguda para pancreatite crônica é um dado controverso na literatura, havendo vários autores que as consideram duas afecções independentes (NARUSE et al., 1998), enquanto outros afirmam que existe uma progressão da pancreatite alcoólica aguda para pancreatite crônica, como referem Ammann e Muellaupt (1994). Embora a pancreatite aguda e crônica induzida pelo veneno de escorpião em animais tenha sido descrita por vários pesquisadores (BARTHOLOMEW et al., 1976), não existe nenhum trabalho, até o presente momento, que descreva, em um mesmo animal, lesões simultâneas características de pancreatite aguda e de pancreatite crônica nem a demonstração sistemática da progressão de uma pancreatite aguda para uma pancreatite crônica.

Os achados histológicos de uma pancreatite aguda são: 1) destruição proteolítica da substância pancreática; 2) necrose dos vasos com subseqüente hemorragia; 3) necrose gordurosa; 4) reação inflamatória. A extensão e a predominância de cada um desses achados depende da duração e da gravidade do processo. No início, apenas edema intersticial; depois, áreas de franca necrose focal e confluente de células endócrinas e exócrinas e na gordura pancreática e peripancreática.

O veneno de escorpião exerce o seu efeito através da despolarização dos terminais nervosos do sistema nervoso autônomo pela abertura dos canais de sódio, liberando mediadores químicos (acetilcolina, catecolaminas, peptídeos) dessas terminações (FREIRE-MAIA; PINTO, 1974), que podem constituir-se em estimulo apropriado para aumentar substancialmente a secreção de glândulas exócrinas do trato gastroin- 
testinal, principalmente glândulas salivares (ANDRADE; SANTOS; BERALDO, 1981), estômago (GONZAGA et al., 1979) e pâncreas e induzir a degranulação de mastócitos e de outras células, que podem liberar substâncias, tais como histamina, serotonina, peptideos e citocinas, todas capazes de provocar alterações vasculares que levam a edema e aumento de secreção pancreática e mesmo a induzir pancreatite aguda.

Se essas alterações agudas progridem para um quadro de pancreatite crônica ainda não está demonstrado, exceto pelo presente trabalho. Não se sabe por qual mecanismo uma única injeção de veneno é capaz de provocar uma pancreatite crônica. É possivel que as lesões estabelecidas na fase aguda lesem as células glandulares e ductais do pâncreas, com extravasamento de enzimas e proteinas para o espaço intersticial, com conseqüente reação tecidual e formação de fibrose, caracteristica da pancreatite crônica.

Como os mastócitos podem também ser estimulados para produzir novas moléculas que medeiam uma resposta inflamatória sustenta-

\section{Abstract}

Modifications in the tenor of several components of the pancreatic secretion and histopathologic alterations of rats'pancreas are noticed after injection of venom from the scorpion Tityus serrulatus. Among those alterations, acute and chronic pancreatites can be mentioned after an only venom injection. The compatible discoveries with acute pancreatites are found from 10 minutes on after the intoxication, and, 20 days later, most of the animals show histologic findings typical of chronic pancreatites. The aim of the present study was to determine the kinetics of the pancreatic alterations that occur after the intravenous injection of non-purified venom scorpion in rats. After the animals fast for 24-48 hours, 0,2 ml of a solution of chloride of sodium (group control) or $0,2 \mathrm{ml}$ of a solution containing $300 \mathrm{mg} / \mathrm{ml}$ of non-purified venom scorpion Tityus serrulatus $(60 \mathrm{mg}$ /animal) were injected directly into their penis vein. They were sacrificed in groups from 5 to 10 each, every 10, 20 and 40 minutes and $1,2,3,4,6,8,10,12,14,16,18$ and 20 days after the injection. The pancreas was removed and processed for histologic study. Acute pancreatite (PA) was observed in the groups sacrificed 10, 20 and 40 minutes, 24 and 48 hours after the injection. Compatible discoveries with chronic pancreatites (PC) were detected in the animals sacrificed between 4 and 20 days after the injection. In the group of animals sacrificed 3 days later, characteristic alterations of PA (desgranulation, acinar vacuolation, diffuse infiltration of lymphocytes and granulomatoses lesions) were observed in the same animal and sometimes in the same histologic piece, and, surprisingly, alterations of PC (dilation ductal with proteics rolhas, hyperplase ductal and hyperplasia of the peripancreatic linphnodes) were also observed, characterizing the transition phase from the acute pancreatites to the chronic pancreatites. All the groups presented mast cells mobilization and degranulation suggesting the participation of mast cells in the etiopathogenese of those lesions. In 50\% of the animals of the groups sacrificed on the 18th and 20th days after the venom, hyperplase of the islets of Langerhans were also observed, besides inflammatory lesions.

\section{Key words}

Acute pancreatites, chronic pancreatites, pancreatic secretion, scorpion venom da, e os dados histológicos apontam para uma estimulação dos mastócitos pela injeção do veneno do escorpião Tityus serrulatus, é possivel que uma resposta sustentada dos mastócitos possa ser a explicação para as alterações de longa duração, com aspecto de cronicidade, observadas nos ratos estudados, caracterizando o quadro típico de pancreatite crônica.

\section{Conclusões}

Podemos concluir, portanto, que o veneno bruto do escorpião é capaz de determinar quadros histopatológicos de pancreatite em ratos, podendo ser detectado o período de transição do quadro agudo para o crônico. A degranulação de mastócitos nestes animais pode representar um fator importante na patogênese da lesão aguda e crônica do pâncreas. Entretanto, outros estudos deverão se seguir para melhor avaliação e entendimento do aparecimento da lesão crônica com uma única dose de veneno.

\section{Agradecimentos}

UFBA, FAPESB, CNPq. 


\section{Referências}

AMMANN, R. W.; MUELlAUPT, B. Progression of alcoholic acute to chronic pancreatitis. Gut, n. 35, p. 552556, 1994.

ANDRADE, S. P.; SANTOS, R. A. S.; BERALDO, W. T. Comparative study of the action of purified scorpion toxin (tityustoxin) on the submandibular and parotid glands of the rat. Toxicon, v. 19, n . 2, p. 255-261, 1981.

BARTHOLOMEW, C. Acute scorpion pancreatitis in Trinidad. Br. Med. J., n. 1, p. 666-668, 1970.

BARTHOLOMEW, C. et al. Experimental studies on the etiology of acute scorpion pancreatitis. Br. J. Surg., n. 63, p. $807-810,1976$.

FREIRE-MAIA, L.; PINTO, J. Mechanism of cardiovascular effects produced by purified scorpion toxin in the rat. Toxicon, n. 8, p. 132, 1974.

GONZAGA, H. M. S. et al. Gastric secretion induced by scorpion toxin. Toxicon, n. 17, p. 316-318, 1979.

MOHAMED, A. H. et al. Histopathological effects of Naja haje snake venom and a venom gland extract of the scorpion Buthus quinquestriatus on the liver, suprarenal gland and pancreas of mice. Toxicon, n. 16, p. 253-261, 1978.
NARUSE, A. S. et al. Chronic pancreatitis: oversaw of medical aspects. Pancreas, v. 16, n. 3, p. 323-328, 1998.

NOVAES, G. et al. Effect of purified scorpion toxin (Tityustoxin) on the pancreatitis secretion on the rat. Toxicon, v. 20, n. 5, p. 847-853, 1982.

NOVAES, G. et al. Experimental chronic interstitial pancreatitis induced by scorpion toxin in rats. Arq. Gastroenterol., São Paulo, v. 27, 1. 4, p. 187-190, 1990.

NOVAES, G. Indução de pancreatites aguda e crônica com uso de toxina do escorpião Tityus serrulatus: modelo experimental em ratos. 1995. 89 f., il. Tese (Doutorado em Ciências Biológicas) - Escola Paulista de Medicina, UNIFESP, São Paulo

NOVAES, G. et al. Induction of acute and chronic with the use of the toxin of the scorpion Tityus serrulatus: experimental model in rats. Arq. Gastroenterol., v. 25, n. 3 , p. 217-224, 1998.

PANTOJA, J. L. et al. Production of acute hemorrhagic pancreatitis in the dog using venom of the scorpion Buthus quinquestriatus. Dig. Dis. Sci., n. 28, p. 429-439, 1983.

SANKARAN, H. et al. Secretory effect of the venom of the scorpion Tityus trinitatis on rat pancreatic slices. Toxicon, n. 15, p. 441-446, 1977. 